have chosen to swim. But still another stream within the humanistic tradition has flowed on through the centuries-one that has received surprisingly little formal attention from either modern historians or social scientists. This latter perspective is reflected in such an expression as: "Shakespeare was a great writer because he dealt with human problems that transcend both space and time." That is, he treated facets of human action that span eras and diverse cultures. The novelists, playwrights, and other humanists who have received lasting acclaim are often those who have captured and effectively dramatized human failings and achievements that hold for many peoples in many areas.

A rapprochement is possible between the scientifically oriented social scientist and those humanists who seek cross-cultural universals. And is not the search for universals the prime goal of comparative study? To be sure, the social scientist and the generalizing humanist are likely to proceed along rather different methodological pathways. But a healthy respect for one another and mutual give-and-take are not only feasible but essential.

On the other hand, scholars committed to a scientific value system will find it difficult, if not impossible, to communicate with those humanists who, like Dr. Thrupp in her review, lay stress upon the search for differences and for unique patterns in socio-cultural development.

I am tempted to offer still other observations. Dr. Thrupp's discussion of my use of the "constructed type" suggests that she is not familiar with the Howard Becker tradition in sociology. And I could comment at some length on the nature and use of historical evidence. But such sallies would lead us far afield, for my aim has been to focus attention upon the need for comparing social units or processes that are comparable-and studying similarities in order to effectively interpret and understand the impact of differing value systems. Only in this manner can we achieve a sound basis for a comparative study of history and society and forge a common bond between the humanist and the social scientist.

GIDEON SJOBERG

University of Texas

\title{
REPLY: OUR OBJECTIVES
}

One of my hopes as Editor is to foster debate that will remain amicable or at least impersonal. The advice that Professor Sjoberg tenders and his protest against my criticism of his work on "The Pre-Industrial City" deserve an amicable reply. Since $C S S H$ has lately imposed on the publisher's goodwill by exceeding its contractual length, the reply will be briefly directed to three questions: Should CSSH devote itself exclusively to historical sociology of the kind that concentrates on structural uniformities? Is it a waste of time 
to look at differences as well as at similarities? How carefully should a generalist handle his evidence?

The answer to the first question is simple. CSSH is not a chapel but a forum and as such is open to anyone with fresh ideas for bringing order into the rapidly expanding vistas that sociological, anthropological and historical research are now exploring. It can justifiably exclude only confused thinking, poor scholarship, discourse of interest to only one discipline and, hopefully, bad writing. In its short four-year life it has already brought into fruitful cooperation many individuals formerly working alone on one problem or difficulty in a single field who together were then able to order it in a comparative perspective relating it to other problems more susceptible of theoretical treatment. Should the editors bar such work in favor of an exclusively universalistic approach? In the present state of research it is my personal opinion that this would be less helpful to the universalists than detrimental. What to the latter at any given moment appear to be important generalizations or illuminating dichotomies may already to research workers, and soon generally, appear banal, simplistic or erroneous. Why this should be so is a question that can invigorate methodological discourse. In this, as on the vexed problem of structural uniformities and other concerns of a universalist approach, $\mathrm{CSSH}$ maintains a panel of discussion through Comment on its more empirical articles. A contributor has suggested that some of its sequences of articles and comment should in time be reissued as separate publications. When it is concluded, one candidate for such republication would be the sequence on the problem of feudalism as a structural uniformity, represented by the outstanding articles by Lawrence Krader in our first issue and by John Hall in this current issue.

Is it then mere dalliance to dwell, as some of our contributors do, on the differences as well as on the similarities that their comparisons disclose? A taxonomist reassembling the skeletons of dinosaurs for museum display would certainly for the time being discard leg bones that did not match those he had already fitted onto the other side of his specimen. He would do so because of his certainty as to dinosaurian skeletal structure. But later the discarded bones might lead him to new discoveries. They might prove to belong to an animal of whose existence he had been unaware, an animal which when reassembled as a whole would at some point upset the accepted scheme of evolutionary theory. In the study of society are we so certain of our structural schemes and theories that we can afford to toss away leg bones that do not fit them? By an odd turn of thought that is perhaps rooted in deficiencies of our language many people would limit the purpose of comparison to that of matching things that are obviously alike. Differences, to be significant, then have to be measurable on a scale. Implicit in this turn of thought is an admission that comparability is relative to our modes of classification. If differences that are not immediately measurable on a scale 
are discarded we may be shutting the door to new ways of viewing phenomena. To say this is not to advocate a passion for opening doors without stopping to scan the view. The function of CSSH is to do both. Tedious exaltation of the scientific curiosity over aesthetic interest in the unique achieves nothing. It is axiomatic that knowledge of what is unique and knowledge of what is general are interdependent and can advance only together. What yesterday was thought to be unique may today in the light of comparisons turn out to be not so.

In presenting a generalization not as part of a theoretical statement but as backed by evidence how careful should the generalist be? In the early days of comparative study evidence favorable to a thesis was culled at random without regard to its context. Work of this kind fell into disrepute. Max Weber through phenomenal labor set new standards and as D. G. MacRae in a recent review article recalls was himself uneasy about the adequacy of his factual knowledge of China. The climate of criticism is now no gentler but with the multiplication of specialists is if anything more severe. In the handling of evidence the generalist has to meet the standards of specialists. He may disregard petty objections about stray exceptions to his statements but not criticism on the score of misinterpretation of evidence or neglect of relevant problems. Professor Sjoberg has perhaps misunderstood the intent of my criticism of his own work. The intent was not to object to his method except as this lent itself to misreading of economic evidence and through neglect of historical literature to overlooking the fact that pre-industrial economic development and political changes furthered by it can significantly alter those structural arrangements of a society to be observed in its cities. The notion that cities are dependent on a free-riding umbrella of social power does not take care of the oversight.

In conclusion it is in order to mention that the Editorial Committee plans in the not too distant future to issue a Supplement to consist of essays on the uses of comparative methods in various fields with emphasis on their relations to current theoretical thinking and to techniques of research. 